\title{
Erostrato: reflexões sobre a retradução de um conto de J ean Paul Sartre
}

\author{
Felipe Cabañas da Silva*
}

Abstract: This paper proposes a reflection about the retranslation of the short story Herostratus, one of the works of the book The Wall, written by J ean Paul Sartre. Starting from the proposal of a new translation for the story, the paper intend to analyse the effects of the lapse of time between both translations, the divergences of interpretation and the different comprehension of translation involved in the two projects.

Keywords: Sartre; retranslation; Herostratus; The Wall.

Resumo: Este artigo propõe uma reflexão a respeito da retradução do conto Erostrato, de J ean Paul Sartre, que integra a coletânea de contos O Muro. A partir da proposta de uma nova tradução para o conto, pretendeu-se analisar os efeitos do lapso de tempo entre as duas traduções, as divergências interpretativas, as distintas concepções tradutórias envolvidas em cada um dos projetos.

Palavras-chave: Sartre; retradução; Erostrato; O Muro.

"Faculdade de Filosofia, Letras e Ciências Humanas - Universidade de São Paulo (USP). Email: fecdasilva@yahoo.com.br. 
Silva, F. C. - Erostrato: reflexões sobre a retradução de um conto de J ean Paul Sartre

\section{Introdução}

0 presente artigo se propôs analisar a retradução do conto Erostrato, de J ean Paul Sartre, que integra a coletânea de contos 0 Muro, publicada em 1939 às vésperas da segunda Guerra Mundial. A partir de um ato prático de tradução pretendeu-se desenvolver reflexões que dizem respeito à teoria da tradução em si, mas também contribuir tanto quanto possível para a tradução do livro.

Antes de iniciar, é imprescindível explicitar o contexto da escolha do autor e da escolha do conto. A escolha da leitura de um autor nunca é aleatória. Há forças que competem neste processo, e uma delas é certamente social, para nos referirmos às ideias de GIDEON TOURY (2000), para quem há um sistema de normas atuante não somente no processo em si de tradução, no indivíduo tradutor, mas também em escolhas e diretrizes editoriais.

Assim, não é demais lembrar que vivemos em uma sociedade que por inúmeras razões lê Sartre e por isso traduz Sartre. É evidente que nada do que dizemos fazer em sociedade diz respeito à totalidade dos indivíduos, mas se refere a eles em termos gerais, e aqui entra a liberdade individual de escolher ler ou não Sartre dentro de uma sociedade que lê Sartre. Em outras palavras, como o objetivo proposto foi traduzir um conto de Sartre e estabelecer reflexões, a partir deste ato de tradução, em comparação a uma tradução precedente e já estabelecida, de H. Alcântara Silveira, é necessário ter em mente que Sartre é um autor fundamental para o pensamento ocidental do século XX e por isso é traduzido em diversas partes do mundo.

Se ler Sartre não tem nada de aleatório, a escolha do conto Erostrato para a realização da tradução que será discutida tem uma história mais peculiar. Em primeiro lugar, um conto é uma obra literária acessível a uma 
Silva, F. C. - Erostrato: reflexões sobre a retradução de um conto de J ean Paul Sartre

discussão tradutória em espaço mais limitado (realizar o mesmo procedimento para um romance exigiria um espaço muito mais extenso).

Como o objetivo primordial desta tradução é o estudo, pela prática, da tradução literária, o ideal foi desenvolvê-la a partir de um conto que ainda não tivesse sido lido. $E$, além do mais, sem qualquer contato com a tradução de H. Alcântara Silveira antes de concluir a tradução do conto. A tradução foi feita, desta forma, como se não houvesse tradução brasileira do livro de Sartre, sem interferências, com o objetivo de realizar uma curiosa experiência de tradução e linguagem.

As surpresas, ao ler a tradução de $\mathrm{H}$. Alcântara Silveira, foram muitas. Surpresas em relação a escolhas tradutórias, escolhas de linguagem, tratamento das ideias do autor, fidelidades e infidelidades. Surpresas que se devem, em primeira instância, a um vácuo de meio século entre as duas traduções. No fundo, o obj eto deste artigo são essas surpresas.

Alguns outros pontos também merecem esclarecimento. 0 livro 0 Muro encontra-se no Brasil em vigésima edição da tradução de H. Alcântara Silveira, e entre o primeiro texto e o último ocorreram revisões editoriais. Ao comparar o texto de 1966, de 1982 e de 1990 pode-se encontrar inúmeras diferenças.

A vigésima edição, de 2005, encontra-se esgotada na Editora Nova Fronteira. Mas, apesar da dificuldade de acesso à última edição, parece claro que tanto maiores serão as diferenças quanto maior for o lapso de tempo. Por isso a decisão de usar como base de comparação o primeiro texto, ainda sem revisões, ou seja, sem nenhuma ação do tempo. Assim, mesmo que a última e mais atual edição estivesse disponível, a escolha seria mantida em função dos objetivos aqui propostos.

0 estudo e a comparação dessas edições e suas transformações é bastante interessante e também uma prova da discussão teórica que aqui será 
Silva, F. C. - Erostrato: reflexões sobre a retradução de um conto de J ean Paul Sartre

central: o fato de as traduções não permanecerem estáticas e intocadas no tempo, e sugerirem sempre revisões, reformulações, ou, simplesmente, retraduções. No entanto, não será possível neste espaço efetuar todas essas comparações e isso talvez possa constituir o obj eto de outro artigo.

\section{Questões teóricas}

\section{1 Tradução e linguagem. Linguagem e tempo}

Uma das formas pelas quais podemos ver a tradução é pela relação que se estabelece entre um povo e outro. Relação inevitável, de aceitação ou estranheza, de paz ou guerra, de compartilhamento de valores ou antagonismo. É fato que os povos se relacionam; com suas amplas diferenças de vivência histórica, língua e cultura, os povos necessitam compartilhar um espaço terrestre amplamente conhecido e explorado em seus menores recantos.

Se o primeiro impulso (e o mais primário) da tradução é o convívio, ela surge como mediadora. Mediadora da necessidade elementar da comunicação. Por trás das línguas, como superfície, a linguagem, como núcleo comum resgatado. Neste sentido, podemos pensar a tradução dentro da situação mítica de Babel. Nas palavras de J acques Derrida:

A "torre de Babel" não configura apenas a multiplicidade irredutível das línguas, ela exibe um não-acabamento, a impossibilidade de completar, de totalizar, de saturar, de acabar qualquer coisa que seria da ordem da edificação, da construção arquitetural, do sistema e da arquitetônica. 0 que a multiplicidade de idiomas vai limitar não é 
Silva, F. C. - Erostrato: reflexões sobre a retradução de um conto de J ean Paul Sartre

apenas uma tradução "verdadeira", uma entr'expressão [entr'expression] transparente e adequada, mas também uma ordem estrutural, uma coerência do constructum (DERRIDA 2002: 12) [grifos do autor].

Quando Deus condenou o homem à não compreensão nasceu a tradução. Mediadora da multiplicidade dos idiomas que entre eles resgata algo em comum. 0 que é este algo em comum? Precisamente a linguagem, a faculdade humana essencial de representar o mundo em signos ${ }^{2}$ e comunicáIo.

A teoria da linguagem é vasta, multidisciplinar e ultrapassa o espaço de um artigo. Filósofos se debruçaram sobre ela durante toda a história da filosofia e os linguistas a compreendem sob diferentes vieses. Também é fundamental para a antropologia, a psicologia e as ciências cognitivas, entre outras ciências que, em algum momento e de alguma forma, precisam reportar-se à linguagem.

Por isso, como para a maioria dos fenômenos humanos, não há definição única e universal, não há conceitualização definitiva. Não há a Verdade definitiva, com "v" maiúsculo, que o homem tanto busca em todas as coisas. Neste sentido, estamos nos reportando ao pensamento de Friedrich Nietzsche. Segundo Rosemary Arroj o:

(...) Nietzsche desmascara a grande ilusão sobre a qual se alicerçam nossas "verdades", nossa filosofia, nossas ciências, o pensamento que chamamos de "racional". Segundo Nietzsche, toda "verdade" estabelecida como tal foi, no início, apenas um "estímulo nervoso". Todo sentido que chamamos de "literal" foi, no início, metáfora e somente pode ser uma criação humana, um reflexo de suas

\footnotetext{
2 Signo, aqui, não no sentido saussuriano da conjunção significante-significado, mas no sentido mais abrangente de Peirce, que compreende os signos sob todas as formas e manifestações que assumem linguísticas ou não. Ou seja, signo como o meio da representação.
} 
Silva, F. C. - Erostrato: reflexões sobre a retradução de um conto de J ean Paul Sartre

circunstâncias e, não, a descoberta de algo que the seja exterior (ARROJ o 1993: 17) [grifos do autor].

Mas, apesar de tudo, é interessante atentarmos para a definição de Georges Mounin, um linguista, em seu Dictionnaire de la linguistique. 0 verbete langage é o que se segue:

L'aptitude observée chez tous les hommes à communiquer au moyen
des langues. Ou bien l'ensemble de toutes les langues humaines
considérées dans leurs caractères communs. Ou encore,
improprement, dans l'usage des philosophes, l'aptitude à
communiquer même avec d'autres systèmes que les langues naturelles
(= fonction symbolique). Ou enfin l'ensemble de tous les points de
vue, descriptifs ou explicatifs, concernant tous les aspects,
linguistiques, psychologiques, sociologiques, sémiologiques,
idéologiques, sous lesquels on peut considérer les langues (MounIN
1974: 196).

Embora se reportar a apenas uma definição não dê conta da extensão e da riqueza do debate, a definição de Mounin é interessante por diversos motivos. Apesar de considerar o uso dos filósofos impróprio, em uma crítica velada à consideração da comunicação para além do signo linguístico, a definição de Mounin também deixa transparecer este conteúdo universal da linguagem pulverizado nas línguas, este algo em comum que as línguas embaralham e que é resgatado em um processo de mediação chamado tradução. Mounin, ademais, estende a consideração das línguas a aspectos não exclusivamente linguísticos, incluindo aspectos psicológicos, sociológicos, semiológicos, ideológicos.

As considerações de Nietzsche sobre as nossas verdades, a demolição de uma Verdade existente para fora de nossa constituição humana, podem ser estendidas à linguagem como portadora destas "verdades" - nas aspas de Rosemary Arrojo. Segundo ela: 
Silva, F. C. - Erostrato: reflexões sobre a retradução de um conto de J ean Paul Sartre

As teorias da linguagem que emergem da tradição intelectual do ocidente, alicerçadas no logocentrismo e no que Jacques Derrida chama de "significado transcendental" têm considerado o texto de partida como um objeto definido, congelado, receptáculo de significados estáveis, geralmente identificados com as intenções de seu autor (ARROJ o 1993: 16) [grifos do autor].

Portanto, Arrojo identifica, a partir do pensamento de J acques Derrida, uma história intelectual calcada na centralidade do logos, conceito também espinhoso da história da filosofia e que ganhou diversas definições, segundo as tradições, mas que no pensamento de Derrida pode ser compreendido como a centralidade do signo e da palavra - ou seja, da linguagem - como organizadora de uma razão universal. Assim, podemos dizer que na mais forte e mais tradicional concepção de linguagem, a compreensão da leitura é a que:

atribui ao leitor a tarefa de "descobrir" os significados "originais" do texto (ou de seu autor). Ler seria, em última análise, uma atividade que propõe a "proteção" dos significados originalmente depositados no texto por seu autor. Embutida nessa concepção de leitura, delineia-se a concepção de tradução que tem orientado sua teoria e prática: traduzir é transportar, é transferir, de forma "protetora", os significados que se imaginam estáveis, de um texto para outro e de uma língua para outra (ARROJ o 1993: 16) [grifos do autor].

Ainda segundo Arrojo, é Nietzsche que abre a perspectiva em que 0 homem não é mais visto como um descobridor de verdades originais, absolutas e externas à sua constituição enquanto homem. 0 homem é visto então como "um criador de significados que se plasmam através das convenções que nos organizam em comunidades" (ARRojo 1993: 18). Freud, segundo ela, também viria complementar o pensamento "desconstrutor" de Friedrich Nietzsche acerca das relações entre sujeito e objeto, virando do avesso a noção até então difundida de suj eito, o suj eito cartesiano definido pelo racionalismo: "o homem cartesiano que se definia pelo seu racionalismo passa a definir-se pelo 
Silva, F. C. - Erostrato: reflexões sobre a retradução de um conto de J ean Paul Sartre

desejo que carrega consigo, que molda seu destino e sua visão de mundo, e do qual não pode estar plenamente consciente" (ARRoj o 1993: 18).

Assim, esta desconstrução do logos sugere que vejamos a linguagem em movimento e em relação ao sujeito. Ou seja, a linguagem passa a não ser mais um arcabouço fixo, que organiza significados independentes de um sujeito e de um momento histórico. A linguagem e suas diversas manifestações não são uma estrutura fixa e eterna, onde encontraremos repetidamente os mesmos significados.

A linguagem está inserida no tempo. Os significados passam por verdadeiras revoluções segundo o momento e a cultura: a maneira de conceber e dizer se transforma. A maneira de escrever se transforma. Nossas palavras se transformam.

Basta pensarmos em um exemplo simples, o abismo que há entre a palavra fromage em francês e queijo em português, para vermos que a tradução não pode ser esse resgate de um significado original e estável, não pode ser esta atividade em que a um signo de uma língua corresponde outro, em outra língua, de valor e significado idênticos.

Ora, os franceses possuem diversas associações ligadas a fromage que se perdem na palavra queijo em português. Inúmeros tipos de fromage típicos que desconhecemos e que no fundo não podem tornar-se queijo; serão sempre fromage. Em sentido inverso, podemos fazer as mesmas afirmações no que diz respeito à nossa feijoada, incrivelmente diferente de um cassoulet francês.

Estes são dois exemplos muito simples da complexidade envolvida no processo de significação e tradução. Signos que se referem a coisas análogas no mundo real se distanciam extremamente no tempo e no espaço.

Mas, o que tudo isso sugere em relação à tradução do conto de J ean Paul Sartre? Primeiramente, que tiremos uma carga do original, que não 0 vejamos como um corpo fixo, quase um arcabouço de concreto cujo conteúdo 
Silva, F. C. - Erostrato: reflexões sobre a retradução de um conto de J ean Paul Sartre

original deve ser resgatado com fidelidade inabalável. Sugere, assim, que pensemos o conto de J ean Paul Sartre em suas polissemias.

Sugere também que as traduções tendem a ser revistas, repensadas, reformuladas. Que a linguagem das traduções está vinculada ao tempo e nele tende a perder-se. As traduções podem multiplicar-se no tempo e dialogar, portanto, são objetos temporais. É pela tradução vista em sua inserção no tempo que se faz necessário pensar o fato da retradução.

\section{2 Tradução e retradução}

Um autor central para a teoria da retradução é Antoine Berman que, no artigo La retraduction comme espace de la traduction (1990), busca definir o conceito.

Como o nome do próprio artigo indica, Berman considera a retradução intrinsecamente ligada à tradução. Mais que intrinsecamente ligada, a retradução seria a própria possibilidade de completude/realização accomplissement (BERMAN 1990: 1) - da tradução.

Segundo ele, enquanto os originais permanecem eternamente jovens, as traduções envelhecem. As traduções correspondem a um estado determinado da língua, da literatura, da cultura e por isso pode acontecer, frequentemente em curto espaço de tempo, que elas não respondam mais ao estado seguinte. Por outro lado, no que Berman parece concordar com uma perspectiva desconstrutivista, nenhuma tradução pôde pretender ser "a" tradução, e por isso a possibilidade e a necessidade da retradução estão inscritas na própria estrutura do ato de traduzir. Em suas palavras: 
Silva, F. C. - Erostrato: reflexões sobre a retradução de um conto de J ean Paul Sartre

II faut retraduire parce que les traductions vieillissent, et parce qu'aucune n'est la traduction: par où I'on voit que traduire est une activité soumise au temps, et une activité qui possède une temporalité propre: celle de la caducité et de l'inachèvement (BERMAN 1990, p. 1) [grifos do autor].

Nesta caducidade da tradução, Berman identifica as exceções: traduções que perduram e que, por vezes, têm mais brilho que os originais. São as grandes traduções. Alguns exemplos são: a Vulgata de São J erônimo, a Bíblia de Martinho Lutero, o Plutarco de Amyot, as Mil e uma noites de Galland, o Shakespeare de Schlegel, a Antígona de Hölderlin, o Don Quixote de Tieck, o Paraíso Perdido de Milton por Chateaubriand, o Poe de Baudelaire, o Baudelaire de Stefan George.

"Si toute traduction n'est pas une grande traduction", afirma Berman, "toute grande traduction, elle, est une retraduction" (Berman 1990: 3). Esta correlação não é absoluta. Pode haver uma primeira tradução que seja uma grande tradução, pois a retradução diz respeito não somente a qualquer nova tradução de um texto. Na concepção de Berman, basta que um texto de um autor já tenha sido traduzido para que a tradução dos outros textos deste autor entre no espaço da retradução. No conceito de retradução assim estendido, é simples notar que as grandes traduções se realizam como retraduções:

Il faut tout le chemin de l'expérience pour parvenir à une traduction consciente d'elle même. Toute première traduction est maladroite: se répète ici au niveau historique ce qui advient à tout traducteur: aucune traduction n'est jamais une "première version" (BERMAN 1990:

4) [grifos do autor].

Berman propõe dois eixos fundamentais para abordar a retradução, que chama o kairos e a défaillance (BERMAn 1990: 5). Toda tradução, segundo o autor, é défaillante, ou seja, é falha, é defeituosa, envolve uma 
Silva, F. C. - Erostrato: reflexões sobre a retradução de um conto de J ean Paul Sartre

incompletude, uma imperfeição, forças antitradutivas que são particularmente evidentes nas primeiras traduções. A défaillance (palavra francesa dificilmente traduzível em português) é simultaneamente a incapacidade de traduzir e a resistência à tradução.

Também possui uma dimensão temporal, que faz com que seja em seus primórdios que a défaillance esteja em seu nível mais alto. A retradução surge, assim, da necessidade de reduzir a défaillance original.

Começa a surgir uma multiplicidade de novas traduções, cada uma confrontando-se à sua maneira ao problema da défaillance. Às vezes, dentro desta multiplicidade podemos encontrar uma grande tradução, que, por um momento, suspende a sucessão das retraduções ou diminui sua necessidade.

Mas, a grande tradução só pode surgir no momento favorável, e este momento favorável chama-se kairos, o momento em que brusca e imprevistamente fica suspensa a resistência que engendra a défaillance, a incapacidade de bem traduzir uma obra: "Catégorie temporelle, le kairos renvoie à l'Histoire elle même. À un moment donné, il devient 'enfin' possible de traduire une oeuvre" (BERMAN 1990: 6) [grifos do autor].

Estas ideias de Antoine Berman são fundamentais para uma reflexão sobre a retradução, ou para uma consideração da tradução como fenômeno temporal, de repetição, historicamente marcado. 0 que também é interessante notar é que Berman também considera a impossibilidade de encontrar "a" tradução; nenhuma tradução pode pretender ser "a" tradução, o que a coloca suj eita à riqueza da multiplicidade. 
Silva, F. C. - Erostrato: reflexões sobre a retradução de um conto de J ean Paul Sartre

\section{Erostrato em debate}

Desta forma, foi realizada uma retradução do conto de Jean Paul Sartre. As diferenças, ou as surpresas, como afirmado na introdução, foram nítidas desde uma primeira leitura, despretensiosa, da tradução de $\mathrm{H}$. Alcântara Silveira.

No entanto, é necessário proceder a algum tipo de sistematização. Na leitura, vemos diferenças nítidas, em grande número, e é preciso encontrar critérios para classificá-las, encontrando as principais questões suscitadas.

Os dois fatos mais nítidos e visíveis desde o primeiro contato com as duas traduções: a linguagem da primeira tradução envelheceu, atingiu a caducidade de que fala Berman. Este envelhecimento, é bom que se tenha em mente, não é nenhum tipo de julgamento de valor. Não equivale a dizer que a linguagem renovada é a mais "adequada", ou "correta"; simplesmente, a constatação da ação do tempo, certa e inevitável, e da possibilidade da renovação.

Em segundo lugar, uma questão não necessariamente relativa ao tempo, mas que pode sim ter relações com um momento histórico: a primeira tradução preza primordialmente pelo respeito ao original, prende-se excessivamente a ele, produzindo determinadas construções sintáticas ou utilizando determinado vocabulário que fazem pouco sentido em português.

Evidentemente, um debate recorrente da história da tradução. Friedrich Schleiermacher discute "se o tradutor deixa o autor em paz e leva 0 leitor até ele; ou deixa o leitor em paz e leva o autor até ele" (SCHLEIERMACHER 2001: 43). Um debate recorrente entre uma tradução estrangeirizadora e uma tradução domesticadora, a última alvo da crítica do próprio Antoine Berman em Translation and the trials of the foreign (2000). 
Silva, F. C. - Erostrato: reflexões sobre a retradução de um conto de J ean Paul Sartre

É nítido que nisto também está implicada uma consideração do texto em suas polissemias. Afirmar que podemos produzir uma tradução que se distancie mais do original que outras, para ter cuidado com a língua/cultura de chegada e o leitor da tradução, é afirmar ao tradutor uma margem de manobra dificilmente possível em uma concepção excessivamente rígida do original e do ato de tradução.

Estas são as duas questões fundamentais, primordiais, depreendidas a partir do que foi proposto e, na realidade, já suscitam amplo debate. Todas as outras discussões parecem ser apêndices dessas duas questões principais, como por exemplo, o fato dos textos franceses serem sempre mais ricos em pronomes pessoais, o que exige do tradutor um cuidadoso trabalho de seleção e eliminação de pronomes em determinadas partes do texto. Mas, isto ocorre se 0 tradutor realmente se preocupa com o texto da língua de chegada e não fica excessivamente preso ao original.

Em determinados momentos, percebemos diferenças de sentido entre uma tradução e outra, o que pode tanto ser consequência do lapso de tempo entre as duas traduções quanto de um apego maior ao original em um caso e menor no outro.

A primeira tradução fica visivelmente rente ao original. Já a tradução aqui proposta se distancia um pouco mais, não somente por causa da busca de um texto que seja coeso em português, como também por causa de uma diferente concepção de respeito ao original.

As discussões levantadas na introdução deste artigo também sugerem uma distinta concepção do suj eito tradutor. Não mais o transportador invisível dos significados originais protegidos, mas personagem central; senão central, ao menos visível, aceito, como sugerem por exemplo os trabalhos de AUBERT (1994) e ARRojo (2003). Isto envolve também uma concepção distinta de fidelidade. Como Arrojo sugere, "mesmo que tivermos como único objetivo o 
Silva, F. C. - Erostrato: reflexões sobre a retradução de um conto de J ean Paul Sartre

resgate das intenções originais de um determinado autor, o que somente podemos atingir em nossa leitura ou tradução é expressar nossa visão desse autor e de suas intenções" (ARROj o 2003: 41) [grifos do autor]. Na visão de Arrojo, inclusive, o escritor não é o autor soberano do texto que escreve, pelas múltiplas dimensões envolvidas na atividade de linguagem, que envolvem fatores inconscientes, subjetivos, como discutido anteriormente.

Neste sentido, na tradução aqui proposta foi priorizada uma linguagem mais leve, um texto mais direto, mais fluente, não somente por causa da língua portuguesa, mas também por causa de determinada maneira de ler Sartre. O texto sartreano é direto, seco, os diálogos são curtos, poucas descrições. O tema é árido, a visão do homem é dura e este fala livremente, sem apegos morais e desprezando em determinados momentos a norma culta. Além do mais, o conto Erostrato, especificamente, estabelece uma dura crítica ao humanismo e seu personagem principal encontra-se inteiramente à deriva. Buscou-se preservar tudo isto, com liberdade, mas uma liberdade assistida, se assim se pode chamar.

Mas, obviamente, como discutido, esta é uma concepção da literatura de Sartre e deste conto específico. Como a primeira tradução fica muito rente ao original, algumas coisas se perderam em um excesso de respeito, que prende 0 tradutor e o impede de enxergar o conto de maneira mais abrangente. 0 excesso de pronomes pessoais em português, por exemplo, impede a fluidez do texto, o que não ocorre no francês. Um texto em francês pode ser direto mesmo com excesso de pronomes pessoais, pois em francês não existe o pronome oculto. Já em português, um texto que repita todos os pronomes do texto em francês (o que, diga-se de passagem, não ocorre na tradução de Silveira neste nível de intensidade) seria ilegível.

Com estes pressupostos, procedamos a uma análise exemplificada das duas traduções, lembrando que não se pretende esgotar 0 assunto e que 
Silva, F. C. - Erostrato: reflexões sobre a retradução de um conto de J ean Paul Sartre

restarão ainda muitos aspectos não discutidos a propósito da tradução específica deste conto, aspectos que podem ter passado despercebidos e podem ser objeto de outras reflexões. Não se pretende, também, de forma alguma, censurar o primeiro tradutor ou propor diretrizes à tradução de Sartre ou do conto sartreano.

\subsection{Linguagem renovada}

Desta forma, retomando BERMAN (1990), as traduções envelhecem, pois correspondem a um estado determinado da língua, da literatura e da cultura, deixando de responder ao estado seguinte.

Neste sentido, é o primeiro choque na comparação entre a primeira tradução e a retradução: a retradução parece mais leve, mais fluente, melhor adaptada ao contexto. A primeira tradução já parece nitidamente deslocada.

Procurou-se elencar o máximo de exemplos, do início ao fim do conto, relacionando original, tradução e retradução, de marcas de um envelhecimento da linguagem. De modo geral, as diferenças são bastante nítidas e marcantes.

Mas, alguns aspectos centrais e mais recorrentes incluem, em primeiro lugar, uma colocação pronominal em mesóclise ou ênclise que hoje em dia procuramos evitar. Atualmente, é mais corrente usarmos a próclise, principalmente na fala direta de um personagem, como é o caso de praticamente todo o conto, narrado em primeira pessoa pelo personagem principal.

Este é um exemplo de construção sintática que cai em desuso ou parece deslocado no tempo. 0 mesmo acontece com determinadas palavras, determinados usos vocabulares que também parecem desgastados. 
Silva, F. C. - Erostrato: reflexões sobre a retradução de um conto de J ean Paul Sartre

O uso da mesóclise é bastante frequente na tradução de Silveira e contribui mais que a ênclise, usada quando necessário na retradução, para certa aura de envelhecimento. Na retradução, as mesóclises estão ausentes, justamente porque ao seu tradutor lhe parece ultrapassado usar mesóclises. Um excesso de mesóclises em um tradutor atual é praticamente motivo de censura em relação a uma linguagem excessivamente rebuscada.

Um período verbal que também parece contribuir consideravelmente para uma impressão de envelhecimento ou deslocamento da primeira tradução é o pretérito mais-que-perfeito, usado em poucas ocasiões por Silveira para traduzir o passé-composé, passé du conditionnel ou imparfait de I'indicatif. Ocorre poucas vezes, mas na retradução foram escolhidos outros tempos verbais ${ }^{3}$.

\section{Quadro 1. Uso do pretérito-mais-que-perfeito}

\begin{tabular}{|l|l|l|l|}
\hline & Original & 1a tradução & Retradução \\
\hline 1 & Était tombé (p. 80) & Caíra (p. 66) & tinha caído (p. 20) \\
\hline 2 & s'était mise (p. 84) & se pusera (p. 69) & tinha ficado (p. 22) \\
\hline 3 & $\begin{array}{l}\text { je I'avais ahurie } \\
\text { (p. 85) }\end{array}$ & eu a perturbara (p. 71) & $\begin{array}{l}\text { eu a tinha abalado (p. } \\
23)\end{array}$ \\
\hline 4 & $\begin{array}{l}\text { J'avais glissé (p. } \\
86)\end{array}$ & Eu enfiara (p. 71) & Eu escorregava (p. 24) \\
\hline 5 & $\begin{array}{l}\text { n'avais jamais } \\
\text { entendu (p. 88) }\end{array}$ & jamais ouvira (p. 73) & $\begin{array}{l}\text { jamais tinha ouvido } \\
\text { (p. 25) }\end{array}$ \\
\hline 6 & j'aurais voulu (p. & desejara (p. 75) & gostaria (p. 26) \\
\hline
\end{tabular}

\footnotetext{
${ }^{3}$ As referências bibliográficas de original e primeira tradução são, respectivamente, SARTRE (1998) e SARTRE (1966). A retradução encontra-se em anexo no final do artigo.
} 
Silva, F. C. - Erostrato: reflexões sobre a retradução de um conto de J ean Paul Sartre

\begin{tabular}{|l|l|l|l|}
\hline & $91)$ & & \\
\hline 7 & $\begin{array}{l}\text { je m'étais entendu } \\
\text { (p. 93) }\end{array}$ & Contratara (p. 77) & me entendi (p. 27) \\
\hline 8 & $\begin{array}{l}\text { j'avais fait } \\
\text { constuire (p. 95) }\end{array}$ & eu mandara construir (p. 78) & $\begin{array}{l}\text { eu tinha construído (p. } \\
28)\end{array}$ \\
\hline 9 & $\begin{array}{l}\text { Tout était d'un } \\
\text { silence (p. 98) }\end{array}$ & $\begin{array}{l}\text { Tudo mergulhara num silêncio } \\
\text { (p.81) }\end{array}$ & $\begin{array}{l}\text { Pairava um silêncio (p. } \\
\text { 29) }\end{array}$ \\
\hline
\end{tabular}

Segue, a seguir, quadro com todos os exemplos elencados de marcas de um envelhecimento da linguagem, que incluem exemplos de vocabulário, construções sintáticas e também uso verbal. 0 objetivo é apenas sugerir através dos exemplos. Para uma visão mais completa é necessário, sem dúvida, uma leitura completa do original, da tradução e da retradução. Mas, embora alguns exemplos fiquem fora de contexto, podemos ter uma ideia bastante completa das diferenças existentes por causa do lapso de tempo.

\section{Quadro 2. Marcas de envelhecimento da linguagem}

\begin{tabular}{|l|l|}
\hline Original & épaules (p. 79) \\
\hline $\mathbf{1}$ a tradução & espáduas (p. 65) \\
\hline Retradução & ombros (p. 20) \\
\hline $\mathbf{2}$ & Je me penchais et je me mettais à rire: (p. 79) \\
\hline & Eu me debruçava a rir; (p. 65) \\
\hline $\mathbf{3}$ & Eu me pendurava e começava a rir: (p. 20) \\
\hline
\end{tabular}


Silva, F. C. - Erostrato: reflexões sobre a retradução de um conto de J ean Paul Sartre

\begin{tabular}{|c|c|}
\hline & toute ma vie. (p. 79) \\
\hline & $\begin{array}{l}\text { A sacada de um sexto andar - eis onde eu deveria passar } \\
\text { tôda a vida. (p. 65) }\end{array}$ \\
\hline & $\begin{array}{l}\text { Na varanda de um sexto andar: é onde eu deveria ter } \\
\text { passado toda a minha vida. (p. 20) }\end{array}$ \\
\hline \multirow[t]{3}{*}{4} & Voilà pourquoi (p. 79) \\
\hline & Eis porque (p. 65) \\
\hline & É por isso (p. 20) \\
\hline \multirow[t]{3}{*}{5} & II était tombé sur le nez. (p. 80) \\
\hline & Caíra de bôrco. (p. 66) \\
\hline & Ele tinha caído de cara no chão. (p. 20) \\
\hline \multirow[t]{3}{*}{6} & $\begin{array}{l}\text { Mais s'ils avaient pu deviner la plus infime partie de la } \\
\text { vérité, ils m'auraient battu. (p. } 80 \text { ) }\end{array}$ \\
\hline & $\begin{array}{l}\text { Mas se pudessem adivinhar a mais ínfima parcela da verdade } \\
\text { ter-me-iam batido. (p. 66) }\end{array}$ \\
\hline & $\begin{array}{l}\text { Mas se tivessem descoberto a mais ínfima parcela da } \\
\text { verdade, teriam me batido. (p. 20) }\end{array}$ \\
\hline \multirow[t]{3}{*}{7} & $\begin{array}{l}\text { Ils m'envoyaient en riant des coups de pieds dans le } \\
\text { derrière. (p. 80) }\end{array}$ \\
\hline & Aplicaram-me, a rir, pontapés no traseiro. (p. 66) \\
\hline & Me deram chutes no traseiro, rindo às gargalhadas. (p. 20) \\
\hline \multirow[t]{2}{*}{8} & $\begin{array}{l}\text { Une blonde qui fait le quart devant un hôtel de la rue du } \\
\text { Montparnasse. (p. 81) }\end{array}$ \\
\hline & $\begin{array}{l}\text { Uma loira que se postava em frente a um hotel da rua } \\
\text { Montparnasse. (p. 67) }\end{array}$ \\
\hline
\end{tabular}


Silva, F. C. - Erostrato: reflexões sobre a retradução de um conto de J ean Paul Sartre

\begin{tabular}{|c|c|}
\hline & $\begin{array}{l}\text { Uma loira que faz ponto na frente de um hotel da rua } \\
\text { Montparnasse. (p. 21) }\end{array}$ \\
\hline \multirow[t]{3}{*}{9} & $\begin{array}{l}\text { La femme était assez lourde et s'arrêtait à chaque marche, } \\
\text { pour souffler. (p. 83) }\end{array}$ \\
\hline & $\begin{array}{l}\text { A mulher era muito pesada e se detinha a cada degrau, para } \\
\text { respirar. (p. 68) }\end{array}$ \\
\hline & $\begin{array}{l}\text { A mulher era bastante pesada e parava em cada degrau para } \\
\text { respirar. (p. 21) }\end{array}$ \\
\hline \multirow[t]{3}{*}{10} & $\begin{array}{l}\text { Je me retournai; elle me tendit ses lèvres. Je la repoussai. } \\
\text { (p. 83) }\end{array}$ \\
\hline & Voltei-me; ela me ofereceu os lábios. Repeli-a. (p. 68) \\
\hline & Voltei-me: ela me ofereceu seus lábios e eu a repeli. (p. 22) \\
\hline \multirow[t]{3}{*}{11} & - Déshabille-toi, lui dis-je. (p. 83) \\
\hline & - Dispa-se, disse-Ihe. (p. 68) \\
\hline & - Tire a roupa, disse. (p. 22) \\
\hline \multirow[t]{3}{*}{12} & $\begin{array}{l}\text { La femme ôta sa robe puis s'arrêta en me jetant un regard } \\
\text { méfiant. (p. 83) }\end{array}$ \\
\hline & $\begin{array}{l}\text { A mulher tirou a roupa, depois estacou deitando-me um } \\
\text { olhar desconfiado. (p. 69) }\end{array}$ \\
\hline & $\begin{array}{l}\text { A mulher tirou o vestido e depois ficou parada me olhando } \\
\text { desconfiada. (p. 22) }\end{array}$ \\
\hline \multirow[t]{3}{*}{13} & Ie ramassa (p. 83-84) \\
\hline & apanhou-a (p. 69) \\
\hline & a recolheu (p. 22) \\
\hline 14 & La putain (p. 84) \\
\hline
\end{tabular}


Silva, F. C. - Erostrato: reflexões sobre a retradução de um conto de J ean Paul Sartre

\begin{tabular}{|c|c|}
\hline & A meretriz (p. 69) \\
\hline & A puta (p. 22) \\
\hline \multirow[t]{3}{*}{15} & tranquillement assis dans un fauteuil (p. 84) \\
\hline & refestelado numa poltrona (p. 69) \\
\hline & sentado tranquilamente numa poltrona (p. 22) \\
\hline \multirow[t]{3}{*}{16} & me sourit coquettement: (p. 84) \\
\hline & sorriu-me galantemente: (p. 69) \\
\hline & sorriu graciosamente: (p. 22) \\
\hline \multirow{3}{*}{17} & Elle s'assit sur le lit (p. 84) \\
\hline & Ela sentou-se na cama (p. 70) \\
\hline & Ela sentou na cama (p. 23) \\
\hline \multirow[t]{3}{*}{18} & $\begin{array}{l}\text { Mais je ris de plus belle, alors elle se leva d'un bond et prit } \\
\text { son soutien-gorge sur la chaise. (p. } 85 \text { ) }\end{array}$ \\
\hline & $\begin{array}{l}\text { Mas eu ri ainda mais, então ela se levantou de um salto e } \\
\text { pegou o soutien de sôbre a cadeira. (p. } 70 \text { ) }\end{array}$ \\
\hline & $\begin{array}{l}\text { Mas eu ri ainda mais. Ela se levantou e pegou o sutiã sobre a } \\
\text { cadeira. (p. 23) }\end{array}$ \\
\hline \multirow[t]{3}{*}{19} & Elle l'a pris. (p. 85) \\
\hline & Ela pegou-a. (p. 70) \\
\hline & Ela pegou. (p. 23) \\
\hline \multirow[t]{3}{*}{20} & billet de cinquante francs (p. 85) \\
\hline & cédula de cinqüenta francos (p. 70) \\
\hline & nota de cinquenta francos (p. 23) \\
\hline 21 & menthe (p. 86) \\
\hline
\end{tabular}


Silva, F. C. - Erostrato: reflexões sobre a retradução de um conto de J ean Paul Sartre

\begin{tabular}{|c|c|}
\hline & hortelã-pimenta (p. 71) \\
\hline & menta (p. 23) \\
\hline \multirow[t]{3}{*}{22} & la rue devait leur paraître toute bleue. (p. 86) \\
\hline & a rua devia parecer-Ihes inteiramente azul. (p. 71) \\
\hline & a rua devia Ihes parecer azul. (p. 24) \\
\hline \multirow[t]{3}{*}{23} & J e leur aurais tiré dans les reins. (p. 87) \\
\hline & Atirar-Ihes-ia nos rins. (p. 71) \\
\hline & Atiraria em seus rins. (p. 24) \\
\hline \multirow[t]{3}{*}{24} & Competence blasée (p. 87) \\
\hline & Competência enfastiada (p. 72) \\
\hline & Competência blasé (p. 24) \\
\hline \multirow[t]{3}{*}{25} & J e leur exposai ma conception du héros noir: (p. 88) \\
\hline & Expus-Ihes minha concepção do herói negro. (p. 72) \\
\hline & Eu Ihes expus minha concepção do herói negro: (p. 24) \\
\hline \multirow[t]{3}{*}{26} & $\begin{array}{l}\text { Il voulait devenir illustre et il n'a rien trouvé de mieux que } \\
\text { de brûler le temple d'Éphèse, une des sept merveilles du } \\
\text { monde. (p. 88) }\end{array}$ \\
\hline & $\begin{array}{l}\text { Êle queria tornar-se ilustre e não achou nada melhor do que } \\
\text { incendiar o templo de Éfeso, uma das sete maravilhas do } \\
\text { mundo. (p. 73) }\end{array}$ \\
\hline & $\begin{array}{l}\text { Queria ser ilustre e não encontrou nada melhor que queimar } \\
\text { o templo de Éfeso, uma das sete maravilhas do mundo. ( } p \text {. } \\
\text { 24) }\end{array}$ \\
\hline 27 & $\begin{array}{l}\text { je m'enfermais dans ma chambre et je tirais des plans. ( } p \text {. } \\
\text { 89) }\end{array}$ \\
\hline
\end{tabular}


Silva, F. C. - Erostrato: reflexões sobre a retradução de um conto de J ean Paul Sartre

\begin{tabular}{|c|c|}
\hline & encerrava-me no meu quarto fazendo planos. (p. 73) \\
\hline & ficava trancado no meu quarto planejando coisas. (p. 25) \\
\hline \multirow[t]{3}{*}{28} & $\begin{array}{l}\text { J'ai vu des photos de ces deux belles filles, ces servantes } \\
\text { qui tuèrent et saccagèrent leurs maîtresses. ( } p .92 \text { ) }\end{array}$ \\
\hline & $\begin{array}{l}\text { Tinha visto os retratos dessas duas belas raparigas, duas } \\
\text { criadas que mataram e saquearam suas patroas. (p. 76) }\end{array}$ \\
\hline & $\begin{array}{l}\text { Vi as fotos de duas belas garotas, empregadas que mataram } \\
\text { e roubaram suas patroas. (p. } 26 \text { ) }\end{array}$ \\
\hline \multirow[t]{3}{*}{29} & des trous dans la chair (p. 93) \\
\hline & Orifícios na carne (p. 76) \\
\hline & buracos na pele (p. 27) \\
\hline \multirow[t]{3}{*}{30} & Le 27 octobre (p. 94) \\
\hline & A 27 de outubro (p. 77) \\
\hline & No dia 27 de outubro (p. 27) \\
\hline \multirow[t]{3}{*}{31} & $\begin{array}{l}\text { Je me vis soudain au coeur de cette foule, horriblement } \\
\text { seul et petit. Comme ils auraient pu me faire mal, s'ils } \\
\text { l'avaient voulu! (p. 94) }\end{array}$ \\
\hline & $\begin{array}{l}\text { Vi-me, de repente, bem no meio dessa multidão, } \\
\text { horrivelmente só e pequeno. Como êles teriam podido } \\
\text { fazer-me mal se tivessem querido! ( } p .78 \text { ) }\end{array}$ \\
\hline & $\begin{array}{l}\text { Subitamente estava no meio dessa multidão, terrivelmente } \\
\text { sozinho e pequeno. Como podiam me machucar, se } \\
\text { quisessem! (p. 27) }\end{array}$ \\
\hline \multirow[t]{2}{*}{32} & soixante-dix centimes (p. 94) \\
\hline & setenta cêntimos (p. 78) \\
\hline
\end{tabular}


Silva, F. C. - Erostrato: reflexões sobre a retradução de um conto de J ean Paul Sartre

\begin{tabular}{|c|c|}
\hline & setenta centavos (p. 27) \\
\hline \multirow[t]{3}{*}{33} & $\begin{array}{l}\text { J e l'ai forcée à se mettre à genoux sous la menace de mon } \\
\text { revolver, à courir à quatre pattes; puis je l'ai attachée à un } \\
\text { pilier (p. 95) }\end{array}$ \\
\hline & $\begin{array}{l}\text { Forcei-a a pôr-se de joelhos sob a ameaça de meu revólver, } \\
\text { e a andar de gatinhas, depois prendi-a a um pilar (p. 78) }\end{array}$ \\
\hline & $\begin{array}{l}\text { Forcei-a, com meu revólver, a ajoelhar-se e correr de } \\
\text { quatro. Depois, amarrei-a numa pilastra (p. 28) }\end{array}$ \\
\hline \multirow[t]{3}{*}{34} & $\begin{array}{l}\text { Ces images m'avaient tellement troublé que j'ai dû me } \\
\text { contenter. (p. 95) }\end{array}$ \\
\hline & $\begin{array}{l}\text { Essas imagens perturbaram-me de tal maneira que tive de } \\
\text { satisfazer-me. (p. 78) }\end{array}$ \\
\hline & $\begin{array}{l}\text { Essas imagens me transtornaram tanto que tive de me } \\
\text { contentar. (p. 28) }\end{array}$ \\
\hline \multirow[t]{3}{*}{35} & Les meubles se sont mis à craquer ( $p .95)$ \\
\hline & Os móveis puseram-se a estalar (p. 79) \\
\hline & Os móveis começaram a estalar. (p. 28) \\
\hline \multirow[t]{3}{*}{36} & Je me suis arrêté devant la glace d'une chemiserie (p. 96) \\
\hline & Parei diante do mostruário de uma camisaria (p. 79) \\
\hline & Parei diante da vitrine de uma loja (p. 28) \\
\hline \multirow[t]{3}{*}{37} & $\begin{array}{l}\text { Au bout d'un moment, je vis arriver trois hommes; je les } \\
\text { laissai passer: il m'en fallait six. (p. 96) }\end{array}$ \\
\hline & $\begin{array}{l}\text { Depois de um instante vi chegarem três homens; deixei-os } \\
\text { passar; eu precisava de seis. (p. 79) }\end{array}$ \\
\hline & Após um momento vieram três homens. Deixei passar: \\
\hline
\end{tabular}


Silva, F. C. - Erostrato: reflexões sobre a retradução de um conto de J ean Paul Sartre

\begin{tabular}{|c|c|}
\hline & precisava de seis. (p. 28) \\
\hline \multirow[t]{3}{*}{38} & - II est emmerdant, aussi, ce morpion. (p. 96) \\
\hline & - Como é cacête, êsse chato! (p. 80) \\
\hline & - Ele enche o saco, também, esse moleque. (p. 28) \\
\hline \multirow[t]{3}{*}{39} & J e fis volte-face et je les suivis machinalement. (p. 97) \\
\hline & Voltei-me e segui-as maquinalmente. (p. 80) \\
\hline & Dei meia volta e fui atrás delas, maquinalmente. (p. 28-29) \\
\hline \multirow[t]{3}{*}{40} & Moi, je m’appuyai contre le mur. (p. 97) \\
\hline & Quanto a mim apoiei-me à parede. (p. 80) \\
\hline & Encostei no muro (p. 29) \\
\hline \multirow[t]{3}{*}{41} & $\begin{array}{l}\text { Quand le gros homme me dépassa, je sursautai et je lui } \\
\text { emboîtait le pas. Je voyais le pli de sa nuque rouge ( } p .97 \text { ) }\end{array}$ \\
\hline & $\begin{array}{l}\text { Quando o homem corpulento passou por mim sobressaltei- } \\
\text { me e segui-o. Eu via a prega de sua nuca (p. } 80 \text { ) }\end{array}$ \\
\hline & $\begin{array}{l}\text { Quando o homem gordo passou, tive um sobressalto e } \\
\text { comecei a segui-lo. Via a dobra de sua nuca (p. 29) }\end{array}$ \\
\hline \multirow[t]{3}{*}{42} & II se dandinait un peu (p. 97) \\
\hline & Êle balouçava um pouco o corpo (p. 80) \\
\hline & Andava meio trôpego (p. 29) \\
\hline \multirow[t]{3}{*}{43} & $\begin{array}{l}\text { Tout d'un coup le type se retourna et me regarda d'un air } \\
\text { irrité. Je fis un pas en arrière. (p. 97) }\end{array}$ \\
\hline & $\begin{array}{l}\text { De repente o tipo voltou-se e me ol hou com um ar irritado. } \\
\text { (p. 80) }\end{array}$ \\
\hline & De repente, o homem virou e me olhou irritado. (p. 29) \\
\hline
\end{tabular}


Silva, F. C. - Erostrato: reflexões sobre a retradução de um conto de J ean Paul Sartre

\begin{tabular}{|c|c|}
\hline \multirow[t]{2}{*}{44} & je lui lâchai trois balles dans le ventre. (p. 97) \\
\hline & Disparei-Ihe três balas no ventre. (p. 81) \\
\hline & meti-Ihe três balas na barriga. (р. 29) \\
\hline \multirow[t]{3}{*}{45} & $\begin{array}{l}\text { Je m'enfuis. Je l'entendis tousser. J'entendis aussi des cris } \\
\text { et une galopade derrière moi. (p. 97-98) }\end{array}$ \\
\hline & $\begin{array}{l}\text { Escondi-me. Ouvi-o tossir. Ouvi também gritos e uma } \\
\text { galopada atrás de mim. (p. 81) }\end{array}$ \\
\hline & $\begin{array}{l}\text { Corri. Ouvi o homem tossir. Ouvi gritos também e uma } \\
\text { correria atrás de mim. (p. 29) }\end{array}$ \\
\hline \multirow[t]{3}{*}{46} & Quand je m'en aperçus, il était trop tard: (p. 98) \\
\hline & Quando o percebi, era muito tarde; (p. 81) \\
\hline & Quando percebi era tarde demais: (p. 29) \\
\hline \multirow[t]{3}{*}{47} & Une main se posa sur mon épaule. (p. 98) \\
\hline & Uma mão pousou no meu ombro. (p. 81) \\
\hline & Senti uma mão no meu ombro (p. 29) \\
\hline \multirow[t]{3}{*}{48} & Les gens se mirent à piailler et s' écartèrent. (p. 98) \\
\hline & As pessoas puseram-se a gritar e se separaram. (p. 81) \\
\hline & As pessoas começaram a gritar e se afastaram. (p. 29) \\
\hline \multirow[t]{3}{*}{49} & $\begin{array}{l}\text { Je traversai le café dans toute sa longueur et je } \\
\text { m'enfermai dans les lavabos. ( } p .98)\end{array}$ \\
\hline & $\begin{array}{l}\text { Atravessei o café em todo o seu comprimento e encerrei-me } \\
\text { na privada. (p. 81) }\end{array}$ \\
\hline & Atravessei todo o café e me tranquei no banheiro. (p. 29) \\
\hline 50 & J'élevai mon arme jusqu'à mes yeux et je vis son petit trou \\
\hline
\end{tabular}


Silva, F. C. - Erostrato: reflexões sobre a retradução de um conto de J ean Paul Sartre

\begin{tabular}{|c|c|}
\hline & noir et rond: (p. 98) \\
\hline & $\begin{array}{l}\text { Levantei minha arma até os olhos e vi seu pequeno orifício } \\
\text { negro e redondo; ( } p .81 \text { ) }\end{array}$ \\
\hline & $\begin{array}{l}\text { Levantei a arma até meus olhos e vi o pequeno e redondo } \\
\text { buraco negro: (p. 29) }\end{array}$ \\
\hline \multirow[t]{3}{*}{51} & II devait s'être plaqué de côté contre le mur (p. 99) \\
\hline & Devia estar encostado de lado, à parede (p. 82) \\
\hline & Provavelmente ficou grudado na parede, de lado (p. 30) \\
\hline \multirow[t]{3}{*}{52} & J'eus tout de même envie de tirer (p. 99) \\
\hline & Tive assim mesmo ânsia de atirar (p. 82) \\
\hline & Senti vontade de atirar, de qualquer forma (p. 30) \\
\hline \multirow[t]{3}{*}{53} & $\begin{array}{l}\text { "S'ils me prennent, ils vont me battre, me casser des dents, } \\
\text { ils me crèveront peut-être un oeil." (p. 99) }\end{array}$ \\
\hline & $\begin{array}{l}\text { "Se êles me agarram, vão bater-me, quebrar-me os dentes, } \\
\text { furar-me um ôlho, talvez". (p. 82) }\end{array}$ \\
\hline & $\begin{array}{l}\text { "Se me pegarem vão me bater, quebrar meus dentes, talvez } \\
\text { me arrancarão um olho". (p. 30) }\end{array}$ \\
\hline
\end{tabular}

\subsection{0 original como prisão}

Portanto, outra diferença importante entre as duas traduções é o nível de proximidade ao original. Como já foi sugerido, na tradução aqui proposta considera-se que em determinados momentos é necessário, para melhor traduzir, distanciar-se do original, não traduzir com literalidade excessiva, justamente para não perder o sentido do próprio original. 
Silva, F. C. - Erostrato: reflexões sobre a retradução de um conto de J ean Paul Sartre

Esta diferença marcante entre as duas traduções, como já afirmado, também pode ser uma das consequências do lapso de tempo. Além da questão de uma visão domesticadora ou estrangeirizadora da tradução, existe a defesa de maior liberdade do tradutor, questão que emerge com muita força no final do século XX.

$E$, de qualquer forma, temos dois tradutores diferentes, duas subjetividades diferentes, duas posturas diferentes ante 0 original e 0 ato tradutório. A maior ou menor distância com relação ao original também decorre deste fato.

Ao contrário do envelhecimento da linguagem, aqui não será possível elencar todos os exemplos de um excesso de proximidade, que resulta em inúmeros casos em excesso de literalidade e perda de sentido. Pois, os exemplos são muitos e muito extensos, e envolvem a observação de períodos mais longos. Desta forma, buscaremos transcrever os excertos mais contundentes.

(01) II fallait quelquefois redescendre dans les rues. (...) J 'étouffais. Quand on est de plain-pied avec les hommes, il est beaucoup plus difficile de les considérer comme des fourmis: ils touchent. Une fois, j'ai vu un type mort dans la rue. II était tombé sur le nez. On l'a retourné, il saignait. J'ai vu ses yeux ouverts, et son air louche, et tout ce sang. J e me disais: (p. 80) Às vezes era preciso descer de nôvo até à rua. (...) Sentia-me sufocar. Quando se está na mesma altura dos homens é muito mais difícil considerá-los como formigas; êles esbarram. Uma vez, vi um tipo morto na rua. Caíra de bôrco. Tinham-no virado, sangrava. Vi seus olhos abertos e seu ar espantado e todo aquêle sangue. Dizia de mim para comigo: (p. 66)

Às vezes era preciso sair às ruas. (...) Eu sufocava. Quando estamos na mesma altura dos homens é muito mais difícil vê-los como formigas: eles pegam. Uma vez vi um homem morto na rua. Ele tinha caído de cara no chão. Viraram-no, ele sangrava. Vi os olhos abertos, e o ar estranho, e todo o sangue que escorria. Pensava: (p. 20) 
Silva, F. C. - Erostrato: reflexões sobre a retradução de um conto de J ean Paul Sartre

Neste exemplo, vemos que o tradutor opta por traduzir verbos que começam com "re" em francês com auxílio de "de novo" ou "tornar a". J e me disais se torna "Dizia de mim para comigo". Silveira também traduz type por "tipo", termo pouco usual em português e que faz pouco sentido, deixando o texto menos fluente.

(02) J'étais désolé: je suis un imaginatif et je m'étais vivement représenté le plaisir que je comptais tirer de cette soirée. ( $p$. 82)

Eu estava desolado. Sou um imaginativo e tinha imaginado vivamente o prazer que esperava tirar desta tarde. (p. 67)

Eu estava decepcionado: tenho uma imaginação fértil e tinha representado vivamente o prazer que iria tirar daquela noite. (p. 21)

Aqui, Silveira traduz literalmente je suis un imaginatif como "sou um imaginativo", o que faz pouco ou nenhum sentido em português. Dizemos, preferencialmente, "tenho muita imaginação" ou "tenho uma imaginação fértil". "Desolado" também não é um termo usual em português, ao contrário do francês.

(03) À I'hôtel Stella, il ne restait qu'une chambre libre, au quatrième. (p. 83)

No Hotel Stella não sobrava senão um cômodo livre, no quarto andar. (p. 68)

No hotel Stella só havia um quarto vago, no quarto andar. ( $p$. 21)

A construção il ne restait que é bastante usual em francês, mas "não sobrava senão" não se encaixa na fluência do português. Este procedimento de Silveira é recorrente e na retradução opta-se por usar simplesmente a afirmativa, como no exemplo em questão: "só havia um quarto vago". 
Silva, F. C. - Erostrato: reflexões sobre a retradução de um conto de J ean Paul Sartre

(04) - C'est haut, dit-elle, en essayant de me sourire. (p. 83)

- É alto, disse, ensaiando para sorrir. (p. 68)

- É alto, disse, tentando sorrir. (p. 22)

Aqui, uma visão clara de um excesso de literalidade cujo resultado é incompreensível. Essayer pode significar "ensaiar", mas no contexto significa tentar. "Ensaiar para sorrir" é uma construção que não tem sentido em português e não traduz satisfatoriamente 0 conteúdo do original. A compreensão não é a mesma. Há uma perda.

(05) Je tenais mon revolver de la main gauche, braqué droit devant moi à travers la poche et je ne le lâchai qu'après avoir tourné le commutateur. (p. 83)

Eu tinha o revolver na mão esquerda, apontado para a frente, através do bôlso, e não o larguei senão após haver virado 0 comutador. (p. 68)

Eu segurava o revólver com a mão esquerda, apontado para frente dentro do bolso, e só larguei depois de acender a luz. ( $p$. 22)

Mais uma vez um resultado incompreensível: "virar o comutador". 0 tradutor ateve-se às palavras e não percebeu que necessitava simplesmente fazer compreender o que se passava na cena: um homem acendendo a luz.

(06) Le dimanche, je pris I'habitude d'aller me poster devant le Châtelet, à la sortie des concerts classiques. Vers six heures, j'entendais une sonnerie, et les ouvreuses venaient assuj et ir les portes vitrées avec des crochets. (p. 86)

Habituei-me a ir, aos domingos, colocar-me diante do Châtelet, à saída dos concertos clássicos. Pelas seis horas, ouvia a campainha e as porteiras vinham prender com ganchos as portas de vidro. (p. 71)

Peguei o hábito de ficar na frente do Châtelet, aos domingos, na saída dos concertos clássicos. Em torno das seis horas eu ouvia uma campainha e as portas eram abertas (p.22-23).

Neste caso, Silveira traduz me poster por "colocar-me". É recorrente no conto traduzir se poster por "colocar-se" ou "postar-se", quando em 
Silva, F. C. - Erostrato: reflexões sobre a retradução de um conto de J ean Paul Sartre

português é mais correto e fluente dizer "ficar" ou "estar". Na retradução, optou-se por ocultar a informação assujetir les portes vitrées avec des crochets, por não fazer falta à compreensão e pela fluência do texto. Silveira opta por traduzi-la literalmente.

(07) Je les dégringolais comme des pipes, ils tombaient les uns sur les autres, et les survivants, pris de panique, refluaient dans le théatre en brisant les vitres des portes. (p. 87)

Eu os derrubava como cachimbos de barro, êles caíam uns sôbre os outros e os sobreviventes, tomados de pânico, refluíam para 0 teatro quebrando os vidros das portas. (p. 71)

Eu as derrubava e elas caíam umas sobre as outras. Os sobreviventes, em pânico, voltavam para o teatro quebrando os vidros das portas. (p. 24)

Acima optou-se na retradução por omitir comme des pipes e informar somente que o personagem derrubava as pessoas. Silveira optou por manter, e "cachimbos de barro" não faz sentido algum em português. Também traduziu literalmente refluer. Na retradução optou-se por um verbo mais usual em português.

(08) Quand je descendais dans la rue, je sentais en mon corps une puissance étrange. J'avais sur moi mon revolver, cette chose qui éclate et qui fait du bruit. ( $p .88$ )

Quando desci à rua, senti em meu corpo uma fôrça estranha. Tinha junto a mim meu revólver, essa coisa que explode e faz barulho. (p. 73)

Quando estava na rua, sentia em meu corpo um poder estranho. Levava comigo o revólver, essa coisa que explode e faz barulho. (p. 25)

É recorrente no texto de Silveira a tradução de descendre dans la rue como "descer à rua". Mas, em português esta não é uma forma usual: usa-se, habitualmente, "sair na rua". Neste exemplo, Silveira também traduz 
Silva, F. C. - Erostrato: reflexões sobre a retradução de um conto de J ean Paul Sartre

literalmente J 'avais sur moi como "Tinha junto a mim". Na retradução optouse por dizer mais claramente "Levava comigo".

(09)

\begin{abstract}
"Monsieur,
"Vous êtes célèbre et vos ouvrages tirent à trente mille. Je vais vous dire pourquoi: c'est que vous aimez les hommes. Vous avez I'humanisme dans le sang: c'est bien de la chance. Vous vous épanouissez quand vous êtes en compagnie; dès que vous voyez un de vos semblables, sans même le connaître, vous vous sentez de la sympathie pour lui. (p. 89)

"Senhor - Sois célebre e vossas obras alcançam tiragens de trinta mil exemplares... Vou dizer-vos por quê - é que amais os homens. Tendes o humanismo no sangue: eis a vossa sorte. Desabrochais quando estais em boa companhia; quando vêdes um de vossos semelhantes, mesmo sem conhecê-lo, sentis simpatia por êle. (p. 74)

"Prezado,

"Você é famoso e já vendeu trinta mil exemplares de suas obras. Vou the dizer o motivo: é que você ama os homens. Tem o humanismo no sangue: que sorte. Você gosta de estar em companhia; assim que vê um de seus semelhantes, sente simpatia por ele sem nem mesmo conhecê-lo. (p. 25)
\end{abstract}

Este é um dos momentos mais importantes do conto. Paul Hilbert, o personagem central, escreve uma carta para 102 escritores franceses. 0 conteúdo é uma crítica aguda ao humanismo. Como é uma carta, envolve todo o sistema francês de formalidade, com o uso do pronome "vós" e um tom solene que Silveira tenta importar em sua tradução. Como no português e na cultura brasileira esse sistema de formalidades faz pouco sentido, o resultado é uma carta deslocada, fora de contexto, quase ilegível. Este é um dos exemplos mais contundentes da proximidade em relação ao original da primeira tradução e das diferenças entre tradução e retradução.

Procurou-se na retradução não utilizar o pronome "vós", mas "você", e eliminar qualquer menção a "senhor", que não necessariamente traduz monsieur adequadamente em todas as situações. Além do mais, o original 
Silva, F. C. - Erostrato: reflexões sobre a retradução de um conto de J ean Paul Sartre

repete constantemente 0 pronome vous, repetição mantida na tradução de Silveira. Como afirmado anteriormente, em uma tradução francês/ português é sempre necessário ficar atento à repetição dos pronomes, para não criar um texto pouco fluente em português.

(10) Avant, leurs visages se balançaient comme des fleurs sages audessus de cols de piqué. Elles respiraient I'hygiène et l'honnêteté appétissante. Un fer discret avait ondulé pareillement leurs cheveux. Et, plus rassurante encore que leurs cheveux frisés, que leurs cols et que leur air d'être en visite chez le photographe, il y avait leur ressemblance de soeurs, leur ressemblance si bien pensante, qui mettait tout de suite en avant les liens du sang et les racines naturelles du groupe familial. (p. 92)

Antes, seus rostos se balouçavam como flôres em cima das golas de algodão. Respiravam higiene e honestidade tentadora. Um ferro discreto havia ondulado igualmente seus cabelos. $E$, mais tranqüilizada ainda que seus cabelos frisados, que suas golas e seu ar de visita ao fotógrafo, havia sua semelhança de irmãs, tão bem-pensantes e que punha imediatamente à mostra os laços de sangue e as raízes naturais do grupo familial. (p. 76)

Antes, seus rostos eram como flores suaves sobre as golas de algodão. Elas exalavam higiene e honestidade, os cabelos bem arrumados, quase idênticos, e tinham aquele ar de estar em visita ao fotógrafo. E, ainda mais tranquilizador que tudo isso, havia sua semelhança de irmãs. Semelhança tão nítida que imediatamente deixava transparecer os laços sanguíneos e as raízes naturais do grupo familiar. (p. 26-27)

Este também é um dos exemplos mais contundentes de como Silveira se prende excessivamente ao original. É um período muito complexo em francês, e nitidamente necessita de alguma adaptação para a compreensão do texto em português. Silveira traduz honnêteté appétissante como "honestidade tentadora" e fer discret como "ferro discreto". Na retradução optou-se por omitir estas expressões pouco importantes e ater-se à compreensão do contexto. Também não costumamos dizer "cabelos frisados" em português e sim "cabelos encaracolados", "cabelos crespos" ou "cabelos cacheados". 
Silva, F. C. - Erostrato: reflexões sobre a retradução de um conto de J ean Paul Sartre

Assim, enquanto a primeira tradução fica rente ao original, na retradução optou-se por tornar o período mais fluente e mais compreensível em português.

\subsection{Abrandando o original}

Outro aspecto importante da tradução de $\mathrm{H}$. Alcântara Silveira e que estranhamente vai em sentido oposto ao que acaba de ser analisado, é um abrandamento do texto original. Onde o original é incômodo, onde há vocabulário coloquial e uma fuga maior da norma culta, o tradutor parece não mais querer a mesma proximidade.

Traduz pisser (p. 81) por "urinar" (p. 67). Mas, pisser não é "urinar" e sim "mijar", e esse vocabulário mais coloquial vem do original e é importante que seja mantido.

Traduz putain (p. 84) por "meretriz" (p. 69) e "decaída" (p. 71), abrandando a força do termo em francês, fazendo com que alguma coisa se perca. Assim, na retradução optou-se por manter a força do termo, mais plenamente traduzido como "puta" (p. 22 e 23), pois mais uma vez a linguagem coloquial é importante no contexto do conto.

Também traduz à poil (p. 82) como "nua" (p. 68), mas o sentido é diferente. À poil é mais forte que nu, é "pelado(a)", e também tem a sua importância no contexto. São poucos exemplos, pois o original usa pouco da linguagem coloquial, mas neles fica nítido a tendência ao abrandamento. 
Silva, F. C. - Erostrato: reflexões sobre a retradução de um conto de J ean Paul Sartre

\section{4 Pequenos erros}

Como não poderia deixar de ser, também é possível identificar pequenos erros na primeira tradução. Pequenos detalhes que podem passar despercebidos e que no fundo têm pouca importância para a compreensão geral do texto. Alguns exemplos são: traduzir adjudant (p. 82) por "ajudante" (p. 68), quando adjudant é um posto de hierarquia militar melhor traduzido em português como "suboficial" (p. 21).

Vicieux (p. 84) é traduzido por "viciado" (p. 69). No contexto, vicieux quer dizer "depravado" (p. 22), dando um sentido bastante distinto.

J 'avais glissé ma main droite dans ma poche (p. 86) foi traduzido como "Eu enfiara a mão esquerda no bôlso".

Silveira traduz pertinent (p. 90) por "penitente" (p. 75), palavras completamente distintas, de sentido completamente diferente, somente de grafia quase idêntica. Um erro bastante comum.

Chapeau vert (p. 98) se torna "chapéu vermelho" (p. 81).

De qualquer forma, os erros também contribuem para provar que por trás de uma tradução há sempre um ser humano, que é imperfeito e tem limitações, e não tem o controle de absolutamente todos os aspectos de sua tradução. Aqui estabelece-se uma nova tradução, de uma outra subjetividade, de um outro momento histórico e, tanto quanto a primeira, está sujeita às imperfeições, embora, todo tradutor se esforce para realizar o melhor trabalho possível. 
Silva, F. C. - Erostrato: reflexões sobre a retradução de um conto de J ean Paul Sartre

\section{Considerações finais}

O objetivo aqui proposto foi realizar um exercício de prática de tradução e em seguida a reflexão teórica a partir desta prática, um exercício de comparação entre a primeira e a segunda tradução, que chamamos retradução, a partir fundamentalmente da teoria de Antoine Berman.

Uma primeira consideração fundamental é a dificuldade de estabelecer uma comparação absolutamente completa, que mapeie sem exceções todos os fatores de divergência entre os dois trabalhos tradutórios. A meta foi, portanto, identificar os eixos principais que diferenciam tradução e retradução, seja pela distinção entre os dois sujeitos tradutores envolvidos, sej a pelo lapso de tempo decorrido entre os dois trabalhos.

$\mathrm{Na}$ realidade, tanto as divergências subjetivas entre os sujeitos e os agentes da tradução, ou seja, os tradutores, quanto a diferença entre as duas traduções por causa da distância no tempo, têm uma essência comum: o fato dos textos e das traduções não serem estruturas fixas e imutáveis, quase sólidas, em que não se permite divergências e transformações.

Traduzir e retraduzir: a partir de uma visão não restrita da tradução é o que parece emergir como reflexão central. A tradução é um exercício complexo, que envolve muitos sujeitos e a passagem do tempo histórico. A tradução só atinge sua completude pela repetição: é um jogo de tentativa e erro. E é nisto que se justifica a decisão de traduzir obras já traduzidas, a atitude de retraduzir. Atitude que se mostra necessária para 0 amadurecimento das traduções.

Por causa da dificuldade envolvida nas comparações, ficou claro que as marcas de envelhecimento da linguagem que elencamos são apenas alguns aspectos do conto. A sensação de deslocamento, a impressão da passagem do 
Silva, F. C. - Erostrato: reflexões sobre a retradução de um conto de J ean Paul Sartre

tempo na leitura, só se dá na leitura completa. Infelizmente, algo difícil de ser comunicado em quadros e tabelas é a impressão da leitura que envolve toda a nossa sensibilidade literária e só pode ser encontrada pela leitura completa. 0 que se buscou foi formalizar alguns aspectos deste envelhecimento e estabelecer uma maneira funcional de identificá-lo no texto.

Da mesma forma, um mea culpa se faz necessário quanto às questões de proximidade e distância em relação ao original. Seria possível elencar 0 dobro de exemplos, mas os exemplos elencados cumpriram a meta de estabelecer os fatores mais importantes de divergências entre primeira tradução e retradução, no que diz respeito à proximidade ou distância. E isto envolve questões teóricas complexas que dizem respeito a literalidade e adaptação, domesticação e estrangeirização. Se não foram aqui aprofundadas é porque não eram o centro da reflexão.

Embora tenhamos identificado outras tendências de tradução, como o abrandamento do original, os dois aspectos centrais identificados a partir do trabalho tradutório e das reflexões aqui estabelecidas foram 0 envelhecimento da linguagem e a maior distância do original por parte da retradução.

0 que é importante que fique claro é que estes são os dois principais fatores de divergência entre duas traduções brasileiras do conto Erostrato de Jean Paul Sartre e não necessariamente são reflexões que podem ser estendidas a outras traduções que envolvam os mesmos momentos históricos ou a outras traduções de Sartre.

E, apesar das dificuldades de estender as reflexões a outras obras de Sartre, ao menos as reflexões sobre a tradução do conto Erostrato estabelecem bons fundamentos para um projeto de retradução dos outros 
Silva, F. C. - Erostrato: reflexões sobre a retradução de um conto de J ean Paul Sartre

contos do livro 0 Muro. Se assim for, as reflexões aqui estabelecidas terão chegado a bom termo.

\section{Referências bibliográficas}

ARRoj O, R. A que são fiéis tradutores e críticos de tradução? Paulo Vizioli e Nelson Ascher discutem John Donne. In: Tradução, desconstrução e psicanálise. Rio de J aneiro: Imago. 1993, Cap. 1, p. 15-26.

. Oficina de tradução. A teoria na prática. 4 ed. São Paulo: Ática, 2003.

AUBeRT, F.H. As (in)fidelidades da tradução. Servidões e autonomia do tradutor. 2 ed. Campinas: Editora Unicamp. 1994.

BERMAn, A. La retraduction comme espace de la traduction. PALIMPSESTES, v. 1, n. 4, p. 1-7, Out. 1994.

. Translation and the trials of the foreign. Tradução de Lawrence Venuti. In: VENUTI, L. The translation studies reader. London: Routledge, 2000. p. 284-297.

DeRRIDA, J. Torres de Babel. Tradução, prefácio e notas: Junia Barreto. Belo Horizonte: Editora UFMG, 2002. $74 \mathrm{p}$.

Mounin, G. Dictionnaire de la linguistique. Paris: Presses Universitaires de France, 1974, p. 340.

SARTRE, J.P. 0 muro. Tradução: H. Alcântara Silveira. 6 ed. Rio de Janeiro: Civilização Brasileira, 1966, p. 209.

. O muro. Tradução: H. Alcântara Silveira. São Paulo: Círculo do Livro S.A, 1990, p. 240.

- O muro. Tradução: H. Alcântara Silveira. Rio de Janeiro: Nova Fronteira, 1982.

. Le mur. Paris: Collection Folio Gallimard, 1998, p. 248.

SCHLEIERMACHER, F. Sobre os diferentes métodos de tradução. In. HeIDERMANN, W. (org.) Florianópolis: UFSC, Núcleo de tradução, 2001. p. 27-87.

TOURY, G. The nature and role of norms in translation. In: VENUTI, LAWRENCE. The translation studies reader. London: Routledge, 2000. p. 198-211. 